\title{
EL LIBRO DE LA CÁMARA DEL CONDE, MI SEÑOR: UNA FUENTE PARA EL ESTUDIO DEL LUJO EN LA CORTE DE LOS CONDES DE PLASENCIA A MEDIADOS DEL SIGLO XV
} $(1453-1455)^{1}$

\author{
EL LIBRO DE LA CAMMARA DEL CONDE, MI SEÑOR: \\ A SOURCE FOR THE STUDY OF LUXURY IN THE COURT OF THE \\ COUNTS OF PLASENCIA OF MID $15^{\text {TH }}$ CENTURY (1453-1455)
}

\author{
Francisco de Paula Cañas Gálvez \\ Universidad Complutense de Madrid \\ franccan@ghis.ucm.es
}

RESUMEN: El libro de la cámara del conde, mi señor, constituye una fuente de extraordinario valor para profundizar en los ámbitos cortesanos de la alta nobleza castellana bajomedieval. Citado parcialmente a lo largo de las últimas décadas por los diferentes estudiosos de la nobleza del período, se publica ahora por primera vez forma completa precedido de un estudio introductorio en el que más allá de la descripción del rico ajuar que rodeaba la vida cotidiana y privada del conde de Plasencia se abordan otros aspectos relevantes como es la formación de una Casa y Corte nobiliaria a imitación y semejanza de la Corte del rey en un largo y lento proceso de consolidación de los ámbitos curiales que por entonces se encontraba en plena expansión en todo el Occidente medieval europeo.

Palabras Clave: Casa y Corte, Condes de Plasencia, Pedro de Estúñiga, Álvaro de Estúñiga, cámara condal, lujo.

ABSCTRACT: El libro de la cámara del conde, mi señor, is a source of extraordinary value for the courtiers areas of late medieval castilian high nobility. Quoted partially along the last decades by different scholars of the nobility of the period, is now published for the first time completely preceded by an introductory study that beyond the description of the rich trousseau surrounding everyday and private life Count of Plasencia other relevant aspects are addressed such as the formation of a household and noble imitation and likeness of the Court of King in a long ans slow consolidation process of the curial areas by then in full expansion around european medieval West.

1. Este trabajo se ha realizado en el marco del proyecto de investigación financiado por el Ministerio de Ciencia e Innovación n ${ }^{\circ}$ HAR2010-16762/HIST titulado "Prácticas de consenso y de pacto e instrumentos de representación en la cultura política castellana (siglos XIII al XV)". 
Keywords: Household, Counts of Plasencia, Pedro de Estúñiga, Álvaro de Estúñiga, county chamber, luxury.

\section{INTRODUCCIÓN}

En el dilatado espectro historiográfico que el estudio de las diferentes sociedades y ámbitos curiales bajomedievales ha trazado en los últimos años ${ }^{2}$ apenas hay menciones al análisis de las Casas y cortes nobiliarias, arzobispales-episcopales y Órdenes Militares hispanas y más concretamente castellanas ${ }^{3}$.

Las razones de tal carencia bibliográfica no son, desde luego, fáciles de determinar con certeza pero muy probablemente obedezcan a la aún reciente incorporación del ámbito áulico como objeto de interés histórico-científico multidisciplinar dentro de la llamada "nueva historia política" $\mathrm{y}$, sobre todo, a la tantas veces referida escasez documental castellana que de una manera particularmente directa afecta al estudio de la vida cortesana en el ocaso de la Edad Media. La falta casi sistemática de los registros cancillerescos y contables y la ausencia acuciante de libros de cámara, tesorería, mayordomos, raciones y quitaciones y resto de oficiales que regularon con su trabajo los distintos aspectos de la vida doméstica de sus respectivas cortes, impide, qué duda cabe, profundizar en los aspectos ya mencionados 5 . Es por ello que la aparición de alguna de estas fuentes anteriores al año 1475 constituye una aportación de primer orden, aunque también limitada

2. Una puesta al día desde los puntos de vista metodológico y bibliográfico en Les entourages princiers à la fin du Moyen Âge. Une aproche quantitative, Études réunies par Alexandra Beauchamp. Madrid, 2013.

3. Para el caso concreto de las cortes episcopales castellanas véanse los trabajos de A. de la Torre. "Servidores de Cisneros", Hispania 23 (1946), pp. 179-241 y los más recientes de J.M. Nieto Soria. Un crimen en la corte. Caída y ascenso de Gutierre Álvarez de Toledo, Señor de Alba (1376-1446). Madrid, 2006, pp. 66-69, sobre Juan Serrano, obispo de Sigüenza; y A. Franco Silva. "La cámara del cardenal Mendoza. Lujo, riqueza y poder de un príncipe de la Iglesia hispana del siglo XV", Historia, Instituciones, Documentos 39 (2012), pp. 65-127. En lo tocante a las casas y cortes de Órdenes Militares citar los estudios de P. Ostos Salcedo. La Orden de Santiago y la escritura. El valor de la comunicación escrita en una orden militar. Los establecimientos de 1440. León, 2008; y J. Ortega Álvarez. "La Casa de Don Gutierre de Sotomayor, Maestre de Alcántara: Una aproximación a la prosopografía de la Orden de Alcántara", Revista de Estudios Extremeños, 2010, Tomo LXVI (1), pp. 239-286.

4. Destacar las aportaciones de M.A. Ladero Quesada. "La Casa Real en la Baja Edad Media", Historia, Instituciones, Documentos 25 (1998), pp. 327-350; J. de Salazar y Acha. La Casa del Rey de Castilla y León en la Edad Media. Madrid, 2000; y V.V.A.A. Evolución y estructura de la Casa Real de Castilla, A. Gambra Gutiérrez y F. Labrador Arroyo (coords.). Madrid, 2010, (2 vols.).

5. Sobre libros y documentos contables nobiliarios bajomedievales véase el trabajo de M.F. Gómez Vozmediano. "La gestión patrimonial de la aristocracia castellana. Burocracia señorial, práctica contable y reflejo documental (siglos XV-XVIII)", en Comercio, banca y sociedad en los reinos hispánicos (siglo XIV-XVIII), Ángel Alloza Aparicio, F. Fernández Izquierdo y Elena García Guerra (eds.). Madrid, 2012, pp. 227-278. 
en algunos de sus aspectos, para el estudio del aparato doméstico de aquellos entornos cortesanos ${ }^{6}$.

Este es el caso del documento que publicamos ahora: El libro de la cámara del conde, mi señor ${ }^{7}$, un inventario de los bienes de las cámaras de Pedro de Estúñiga, conde de Plasencia y justicia mayor del rey, y de su hijo y heredero, Álvaro. Después de una larga vida consagrada al servicio de Juan $\mathrm{II}^{8}$, don Pedro falleció en sus palacios vallisoletanos en julio de $1453^{9}$. Pocos meses después, entre mayo de

6. Para la época de Juan I contamos con las cuentas del camarero real Diego López de Estúñiga, padre de Pedro López de Estúñiga. Archivo Histórico de la Nobleza (AHNOB), Osuna, Leg. 40, nº 1. M.L. Villalobos y Martínez-Pontrémuli. "Las gestiones hacendísticas de Diego López de Estúñiga, camarero de Juan I (Contribución al estudio de la economía y la fiscalidad castellanas bajo los primeros Trastámaras)", Hispania Vol. 43, n 153 (1983), pp. 159-207; y F. de Paula Cañas Gálvez. "La Casa de Juan I de Castilla: aspectos domésticos y ámbitos privados de la realeza castellana a finales del siglo XIV (ca. 1370-1390)" En la España Medieval 34 (2011), pp. 133-180. De relevancia para la corte de Juan II son los estudios de J. M. Nieto Soria. "El tesoro de doña Leonor, esposa de Fernando I de Aragón, en el monasterio de Guadalupe", Acta historica et archaeologica mediaevalia 18 (1997), pp. 39-66; J. Ferrandis Torres. Fuentes documentales para la historia del arte español, III. Madrid, 1949; y F. de Paula Cañas Gálvez. "La cámara de Juan II: vida privada, ceremonia y lujo en la corte de Castilla a mediados del siglo XV", en Evolución y estructura de la Casa Real de Castilla, vol. I. Madrid, 2010, pp. 81-195. Para los reinados de Enrique IV y los primeros años del de los Reyes Católicos M.A. Ladero Quesada. "1462: Un año en la vida de Enrique IV, rey de Castilla”, En la España Medieval 14 (1991), pp. 237-274; y M.A. Ladero Quesada y M. Canatera Montenegro. "El tesoro de Enrique IV en el alcázar de Segovia 1465-1475”, Historia, Instituciones, Documentos 31 (2004), pp. 307-352. Un inventario de Álvaro de Estúñiga fue estudiado por G. Lora Serrano. "La organización de la defensa militar de un estado señorial y el potencial bélico de un noble a mediados del siglo XV", Historia, Instituciones, Documentos 18 (1991), pp. 297-338. Y noticias sobre varios inventarios de la nobleza castellana del siglo XV en A. Franco Silva. La fortuna y el poder: estudios sobre las bases económicas de la aristocracia castellana. Cádiz, 1996. De carácter más general es la obra de M. Martinez Martínez y G. Lora Serrano. "Las inversiones suntuarias de la nobleza a fines de la Edad Media" en Historia y sociabilidad: homenaje a la profesora María del Carmen Melendreras Gimeno, Juan Bautista Vilar Ramírez, Antonio Peñafiel Ramón y Antonio Irigoyen López (coords.). 2007, pp. 197-222.

7. El manuscrito es una pieza más en la testamentaría de don Pedro de Estúñiga y el inventario general de los estados, rentas y bienes del mayorazgo de Plasencia y sus señoríos. AHNOB, Osuna, Legajo 215, Documento 89. Parte de esta documentación ya fue estudiada por M.A. Ladero Quesada. "Rentas condales en Plasencia" en El Siglo XV en Castilla. Fuentes de renta y política fiscal. Barcelona, 1982, pp. 168-189.

8. Fernando de Pulgar cuenta en sus Claros varones de Castilla una anécdota protagonizada por don Pedro que evidencia su fidelidad al rey aún en las circunstancias menos favorables. "Acaesció que como el rey don Juan el segundo oviese necesarias algunas gentes de armas para pacificar los escándalos que estonces en sus reinos avía, este caballero (Pedro de Estúñiga), como quiera que era ya viejo e enfermo e muy gravado de gota, pero en zelo grande que tuvo de servir su rey, se fizo traer en andas al real do estava la hueste e, rodeado de grand copia de gente de armas de su casa, vino a le servir e sirvióle con otros cavalleros de tal manera en aquella jornada que el rey rescibió dél servicio señalado, e él alcanço fama de leal súbdito e fue exenplo de lealtad a otros que se movieron a servir su rey, veyendo venir cómo vino este cavallero en andas a le servir". F. de Pulgar. Claros varones de Castilla, Edición de M. A. Pérez Priego. Madrid, 2007, p. 150.

9. Acerca del papel político, económico, cultural y social de los Estúñigas en general y de don Pedro en particular, véase E. Benito Ruano. "Lope de Estúñiga. Vida y cancionero", Revista de Filología Española LI (1968), pp. 17-20; M.L. Villalobos y Martínez-Pontrémuli. "Los Estúñiga: la penetración de Castilla de un linaje de la nobleza nueva", Cuadernos de Historia 35, Extra 6 (1975), pp. 327-356; M.A. Ladero Quesada. "Los señores de Gibraleón”, Cuadernos de Historia VII (1977), pp. 33-95 y de este mismo autor "Rentas condales...", pp. 168-189; G. Lora Serrano. "Nobleza y 
1454 y enero de 1455, ostentando ya don Álvaro la jefatura de la Casa de Estúñiga, se procedía a concertar este inventario por el camarero condal, Pedro de Pernía. El libro está dividido, como apuntábamos más arriba, en dos partes bien diferenciadas, aunque estrechamente relacionadas entre sí: por una parte el inventario de los bienes de la cámara de Pedro de Estúñiga en el momento de su muerte (1-298), y por otra la recepta o relación de la cámara que Álvaro de Estúñiga tenía en su palacio de Curiel en enero de 1455 (299-547), heredera, en buena parte, de la de su progenitor.

En ambos inventarios se detallan con precisión las joyas, ropas, camas, libros, tapices y demás enseres que rodeaban el ámbito más privado de la vida de los condes de Plasencia en un momento de esplendor político del linaje ${ }^{10}$. Una buena parte de las piezas fueron remitidas al camarero por varios oficiales vinculados a la cámara y Casa condal: Pedro de Valda, Juan de Espinosa, Nuño, Bolaños, Gutierre de Valdelomar, Diego de Valera ${ }^{11}$ o el secretario Sancho González de Valladolid ${ }^{12}$. Otras lo serían por algunos miembros cercanos de la familia de los condes entre los que entonces habían quedado repartidos los numerosos bienes de la cámara, como su propio hijo y heredero, don Álvaro, y la sobrina de don Pedro, Leonor Pimentel, con quien más tarde, en 1458 y tras enviudar de su primera esposa, Leonor Manrique de Lara, contraería matrimonio el mencionado Álvaro de Estúñiga ${ }^{13}$.

monarquía bajo los primeros Trastámaras: el ascenso de Diego López de Estúñiga", Ifigea 3-4 (19861987), pp. 73-108; también de esta misma autora "El ducado de Arévalo (1469-1480). Un conflicto señorial en tierras abulenses a fines de la Edad Media", Historia, Instituciones, Documentos 25 (1998), pp. 369-394 y "Los constructores del Palacio de Altamira. La familia señorial de los Estúñigas", en La restauración del palacio de Altamira. Sevilla, 2005, pp. 126-179; P.M. Cátedra. La historia de la Casa de Zúñiga, atribuida a Mosén Diego de Valera. Salamanca, 2003.

10. Para la nomenclatura de muchas de las piezas detalladas en el inventario remitimos al lector a las obras de M. Gual Camarena. Vocabulario del comercio medieval: colección de aranceles, aduaneros de la corona de Aragón (siglos XIII y XIV). Tarragona, 1968; J. Alfau de Solalinde. Nomenclatura de los tejidos españoles del siglo XIII. Madrid, 1969; y M. Diago Hernando. La industria y el comercio de productos textiles en Europa. Siglos XI al XV. Madrid, 1998.

11. Se desconoce la vinculación concreta que Valera mantuvo con la Casa de los condes de Plasencia así como la fecha exacta de su entrada al servicio de don Pedro. Algunas fuentes nos inducen a pensar que la relación fue muy estrecha. Gracias, por ejemplo, a la crónica de Juan II sabemos que el conde había encomendado a Valera la educación de su nieto Pedro. Por aquellas mismas fechas, 1453, el libro-inventario confirma la presencia de Diego de Valera en la corte condal y tras la muerte de don Pedro, el propio Valera nos asegura que tuvo que “... ir a Sevilla por mandado de don Álvaro, mi señor, con don Pedro d'Estúñiga, su fijo, por fazer su desposorio con doña Teresa de Guzmán, fija de don Juan de Guzmán, duque de Medina Sidonia, donde me detove ocho meses". F. Pérez de Guzmán. Crónica del serenísimo príncipe don Juan, segundo Rey deste nombre. Madrid, 1953, p. 660. C. Moya García. Edición y estudio de "La Valeriana” (Crónica abreviana de España de Mosén Diego de Valera. Madrid, 2009, pp. XXI-XLIII y 338.

12. En la partida 542 aparece entregando al caballerizo del conde don Álvaro, Pedro de Herrera, una "sylla de mula labrada de hueso". Sancho fue escribano de cámara de Juan II (1453) y secretario y criado de Álvaro de Estúñiga (1453-1457). F. de P. Cañas Gálvez. Burocracia y cancillería en la corte de Juan II de Castilla (1406-1454). Estudio institucional y prosopográfico. Salamanca, 2012, p. 392.

13. Debido al grado de consanguinidad fue necesaria bula papal de dispensa de Pío II y autorización de Enrique IV. AHNOB, Osuna, Leg. 215, nº 7. 
Si bien es cierto que este libro de cámara ya fue objeto de atención parcial por parte de los estudiosos de las bibliotecas de la época ${ }^{14}$, también es necesario resaltar que es ahora cuando por primera vez se ha procedido a su transcripción completa. Dada la gran variedad, riqueza y diversidad de las piezas señaladas podemos concluir que los condes de Plasencia gozaban a mediados del siglo XV de una corte pequeña en cuanto al número de sus oficiales, pero sofisticada y exquisita en lo referente al lujo y magnificencia de los mencionados objetos, muchos de ellos ornamentados orgullosamente con las armas y divisas familiares de Estúñigas y Guzmanes ${ }^{15}$, que engalanaban los salones de sus mansiones de Plasencia, Burgos o Valladolid ${ }^{16}$. La belleza de las piezas de plata y oro elaboradas por maestre Hançe, el mismo Hançe de Valladolid, Hançe Dolmo o Hans de Ulm, joyero de origen alemán que trabajó activamente en la corte de Juan II por aquellos mismos años ${ }^{17}$; la excelencia y abundancia de sus pertrechos de guerra que conformaban su cámara de las armas, similar en su estructura y contenidos a la del propio monarca ${ }^{18}$; la elegancia de sus ropas de paño y seda; la calidad de su animales de monta; los once títulos de la biblioteca condal, entre los que figuran una Biblia, varias crónicas de reyes y un Regimiento de príncipes; la calidad y variedad de los tapices, mantas de pared y almáticas que abrigaban y adornaban las estancias de sus aposentos; la predilección por los instrumentos musicales propios del ámbito camerístico hispánico como las dos vihuelas que el conde Álvaro guardaba en sus correspondientes cajas de paño; el libro de rezar cubierto de tapete negro con vna guarniçión de plata, o la elegancia de los perfumes que aromatizaban las estancias, hacían de la corte condal, además de un centro político y cultural de primer orden ${ }^{19}$, un marco curial de boato y lujo para cuyo sustento eran necesarias unas rentas anuales que en el caso que nos ocupa se elevaban hasta los 4.000.000 de maravedíes (ó 26.000 doblas de oro de

14. M.A. Ladero Quesada y M. C. Quintanilla Raso. "Bibliotecas de la alta nobleza castellana en el siglo XV" en Livre et lecture en Espagne et en France sous l'Ancien Régime, Colloque de la Casa de Velázquez. París, 1981, pp. 47-59.

15. En 1407 Pedro había contraído matrimonio con Isabel Elvira de Guzmán, hija de Alvar Pérez de Guzmán, señor de Gibraleón, Olvera y Ayamonte. Las capitulaciones matrimoniales habían sido firmadas años antes, en 1395. AHNOB, Osuna, Carp. 98, Doc. 1.

16. Sobre los palacios segovianos de don Pedro véase F. de P. Cañas Gálvez. El itinerario de la corte de Juan II de Castilla (1418-1454). Madrid, 2007, p. 110.

17. M.V. Herránez Ortega. "De la plata y los plateros del Rey Juan II de Castilla", en Estudios de platería, J. Rivas Carmona (Coord.). Murcia, 2006, pp. 227-289. Sobre este artesano y su trabajo en la cámara de Juan II véase F. de F. de P. Cañas Gálvez. "La cámara de Juan II....”, pp. 158,166 y 171.

18. F. de P. Cañas Gálvez. "La cámara de Juan II...”, pp. 170-174.

19. Como evidencia, por ejemplo, su activa participación junto a su hijo Gonzalo en la caída y muerte del condestable Álvaro de Luna. La detención de don Álvaro en Burgos en la Semana Santa de 1453 fue muy celebrada en la corte condal hasta el punto de premiar al portador de la noticia, Juan de la Quadra, con unas albricias de 10.000 maravedíes. G. Chacón. Crónica de Don Álvaro de Luna, Edición de Juan de Mata Carriazo. Madrid, 1940, pp. 324-325. AHNOB, Osuna, Leg. 215, Doc. 87. 
la banda $)^{20}$, una cuantía que bien podía equipararse a las de las cortes nobiliarias más ricas de Castilla ${ }^{21} \mathrm{o}$, incluso, a la del príncipe Enrique, las reinas consortes o el propio Juan $\mathrm{II}^{22}$.

Con el fin de facilitar la localización y consulta de las piezas citadas se han numerado todas las entradas citadas, por grupos temáticos según aparecen en el manuscrito, con un número señalado en negrita al principio de su descripción que no consta en el documento original. La división y su correspondencia con el número de entrada es, pues, la siguiente:

\section{Libro de la cámara de Pedro de Estúñiga (1453-1454):}

Joyas de oro y plata

Vancales y almohadas

Alfombras

$51-58$

Reposteros

$59-60$

Camas y paramentos de cama

$61-74$

Cosas de lienzo

Ropas de cama

Paños franceses, alfombras, almatifas y alhamares de estrado

Armas

Ropas de paño y seda

Jubones

Ropas de paño y de vestir

Calzas

Arcas, cofres y mesas

Cosas menudas

Lienzos

\section{Recepta de la cámara de Álvaro de Estúñiga (1455):}

Joyas

Ropas de seda y de paño de vestir

Jubones

La cama del conde

20. M.A. Ladero Quesada. "Rentas condales...”, p. 175. También J. Martínez Moro. La renta feudal en la Castilla del siglo XV, los Stúniga: consideraciones metodológicas y otras. Valladolid, 1977.

21. Como la del todopoderoso Álvaro de Luna, que necesitaba un total de 374.000 maravedíes sólo para el pago de los acostamientos a las personas adscritas a su servicio militar; la suma se habría de elevar en 1453 hasta los 879.000 maravedíes por este mismo concepto. J.M. Calderón Ortega. Álvaro de Luna: Riqueza y poder en la Castilla del siglo XV. Madrid, 1998, pp. 315-319.

22. En 1453 el gasto de las raciones de la Casa de Juan II fue de 5.500.000 maravedíes y el de su esposa, Isabel de Portugal, osciló entre el 1.000 .000 y el 1.500 .000 en los años siguientes. El príncipe Enrique y Juana de Portugal dispusieron para idénticos fines de presupuestos de 5.194.480 y 4.772.337 maravedíes respectivamente. F. de P. Cañas Gálvez. "Las casas de Isabel y Juana de Portugal, reinas de Castilla. Organización, dinámica institucional y prosopografía (1447-1496)", en Las relaciones discretas entre las monarquias hispana y portuguesa. Las casas de las reinas (siglos XV-XIX), vol. I. Madrid, 2008, pp. 32 y 35; también F. de P. Cañas Gálvez. "La cámara de Juan II...”, p. 95. 
Cosas de lienzo

353-359

Libros

360-369

Otra ropa de cama

370-377

Paños franceses y alfombras

$378-381$

Otras cosas menudas

$382-416$

Armas

$417-457$

Objetos remitidos por Juan de Pernía a Catalina de Sevilla

458-527

Caballos y mulas

$528-533$

Sillas y frenos

534-544

Ballestas y culebrinas

$545-547$

f. 1 r

\begin{abstract}
Libro de la cámara del conde, my señor.
Que reçibió Nuño por Juan de Pernía, camarero, en Valladolid, que se conçertó en el mes de mayo de cccliiii
\end{abstract}

\title{
Año de iUccccliiii años
}

Conçertado

[Rúbrica]

AHNOB, Osuna, Legajo 215, Documento 89.

\section{f. $1 v$}

f. 2 r

\section{[En blanco $]$}

Nuño

Cargo de la

cámara del

conde, mi señor

Año de

iUccccliiii

Joyas de oro

Estas cosas todas contenydas en esta cuenta que son siete pliegos de papel dio el dicho Nuño muchas cosas a my señora doña Leonor e otras muchas a mosén Diego de Valera. Et requiriese la cámara de las cosas que quedaron en el dicho Nuño en xv días de enero de iUcccclv segund adelante está escripta en este libro. Et por ende lo contenydo en estos siete pliegos de papel non es cosa alguna saluo la dicha cámara que está adelante.

\section{Joyas de oro que resçibió de Gutyerre de Valdelomar del cargo de Juan de Pernía}

1. Vna cadena de oro de caderas en que ay dos rencleras de los cabos de amas partes, que ay en cada parte nouenta muelas de oro, que son çiento e ochenta muelas, e más en medio de la dicha çinta sus tachones de oro como en manera de enfojadura, que non falleçe cosa alguna en ella. E más dos agujas de oro con que se çiñe la dicha çinta. Et vn pañezuelo de canbray con vnas franjas de oro que está en la caxa de la dicha çinta. E vnas medías calças verdes en la dicha caxa. 
2. Vn collar de oro en que ay honze mienbros e quatro esmeraldas grandes e vn balax en medio grande e seys perlas en medio grandes e quarenta e dos perlas por las orellas. Dize Nuño que se desfizo para el collar grande que fizo maestre Hançe.

3. Vn collar de oro en que ay veynte mienbros redondos de esparzidores que pesa vn marco e seys honças escasas.

4. Otro collar de oro en que ay treynta e syete mienbros de laçadas que pesa dos marcos e dos honças e dos ochauas escasas.

5. Vna çinta de texillo negra con cabo e feuilla de oro con esparzidores en el cabo et en la feuilla et con seys chatones e en la dicha çinta vn carniel de damasco negro viejo guarnido en plata.

6. Vna çinta de cuero angosta con cubo de feuilla de oro et vna copa gorja con vna contera de oro.

\section{f. $2 v$}

\section{Lo que resçibió de Pedro de Valda}

7. Vna bozina de oro con seys çafires e çinco balajes e treynta e seys perlas. E más vna jarra que está en la dicha bozina, çinco perlas e dos esmeraldas, et vn diamante pequeño e vn balax. Et más en vna mançana de oro ocho perlas más pequeñas. Et más en dos vergas de oro en que cuelga la bosina syete perlas e quatro esmeraldas e tres balajes.

8. Vn firmalle de oro con vn balax e seys perlas, las çinco perlas se posieron en el collar grande de oro e el fermalle e balax e vna perla reçibiólo my señora.

9. Vna cruz de oro con vna ymajen de Sant Françisco de azauache. Desfízose para el collar del dicho señor.

10. En vn sartal veynte e seys cuentas de oro, las dose grandes e las catorze pequeñas. Desfízose para el dicho collar del dicho señor para el collar grande.

11. Vna cadena de oro que peso ocho marcos e dos honças e tyene setenta e ocho eslauones.

Reçibiólo my 12. Vn rótulo de plata dorada con vnas letras e vn eslauonçillo de oro señora de otra cadena.

Reçibiólo my 13. Vna bolsa verde e leonada et dentro vn pedaço de ynycornio. señora 
Reçibiólo my

señora

Reçibiólo my señora

f. $3 \mathbf{r}$

Reçibiólo my señora

Reçibiólo my

señora

Reçibiólo my señora

Reçibiólo my señora

Reçibiólo my señora

\section{f. $3 v$}

Reçibiólo my señora vn poco de aljófar
14. Vn bolsillo pequeño de seda.

15. Vn texillo morado guarnydo en plata dorada.

16. Ytem, treze morlanes de vna çinta, los nueue con vna perla cada vno, et los tres cada vno con nueue perlas, et vno syn perla. Et estas perlas mandó dar el conde my señor a monsen Diego de Valera para broslar los paramentos de cauallo del dicho señor que fesieron en Valladolid año de iUccccliiii años.

17. Vna mançana de alanbar.

18. Medio cordón en que ha doze nudos de aljófar, el qual aljófar se dio por mandado del conde, my señor, para poner en los paramentos de cauallo e en la çelada del dicho señor, et se dio a mosén Diego de Valera.

19. Más nueue mançanillas de aljófar sueltas, las quales se desataron el aljófar dellas e se dieron para los paramentos e çelada del dicho señor conde al dicho mosén Diego.

20. Vna çinta con veynte e çinco monimentos de plata esmaltados con aljófar e vn cubo con vna florezilla en medio et dos pañizuelos. El qual aljófar se quitó de la dicha çinta e se dio a mosén Diego de Valera por mandado del conde, my señor, para los paramentos e çelada de su merçed.

21. Vna pulsera de tapete negro con vna red de aljófar et çinco firmalles et quatro bastonçillos con tres perlas cada vno esmaltados con verde, los quales dichos çinco firmalles se desfezieron e fízose dellos vn cabo e vna feuilla para vna çinta estrechuela de cuero del conde, my señor, que esta cargada ante desto, et vna contera para vna copa gorja del dicho señor que esta en la dicha çinta, et el otro que sobro desto se dio al dicho mosén Diego de Valera para el collar que fezieron para la señora doña Leonor Pymentel.

22. Vn marco et honça e media de aljófar menudo en vna taleguilla, el qual dicho aljófar se dio al dicho mosén Diego de Valera por mandado del conde, my señor, para los paramentos de cauallo et çelada del dicho señor, et fincó en el dicho Nuño vn poco de aljófar de ello que peso [en blanco]. 


\section{Mas reçebió el dicho Nuño del dicho Pedro de Valda esto que aquí se dirá}

Dióla a don Diego por mandado del conde, my señor

23. Vna çinta de caderas de oro en que ay çiento e veynte e dos tachones de oro gruesos et vna renclera del vn cabo e otra del otro de la çinta, que no falleçe ninguna, et vienen eguales con los otros tachones et non le falleçe ninguno.

24. Otra çinta de caderas de plata sobredorada en tres pedaços pegadisos.

Reçibióla my señora

Reçibióla my señora

Reçibióla my señora

Reçibióla my señora

Reçibióla my señora

Reçibióla my señora

f. $4 \mathbf{r}$

Nuño

Cargo de la cámara del conde, my señor

Reçibiólo my señora

Año de iUccccliiii años

Reçibiólas my señora

Reçibióla my señora

Reçibióla
25. Otra çinta de plata dorada e esmaltada con veynte e seys morlanes et veynte e çinco çençerras dentro en vna caxa.

26. Vna çinta de cuero negro guarnyda de oro con seys tachones e cabo e feuilla et vn brocal.

27. Vn castillejo de plata dorado de elmete en su caxa.

28. Vn collar de plata dorado con canpanillas doradas.

29. Vna cadenilla de hueso et de oro con eslauones de hueso et de oro.

30. Vnas cuentas de hueso et de oro.

31. Otra çinta de cuero blanco con feuilla et cabo et tachones de plata que son çinco tachones et bordada a la morisca et vn esquerón de la dicha obra.

32. Vnas cuentas de azauache gruesas que son doze cuentas.

33. Vna taleguilla con argentería.

34. Vna alua negra verde de ballón. 
Reçibiólas my señora

Reçibiólo my señora

Reçibiólos my señora

Este vancal esta cargado adelante con los vancales f. $4 \mathrm{v}$
Reçibiólos my señora

Reçibiólos my señora

Reçibio my señora xxiii almohadas destrado

\section{Vancales e almohadas}

41. Lo que reçibió Nuño de mi señora doña Leonor en el mes de mayo de liiii:

41. 1. Ocho almohadas de Flandes nuevas llenas.

41. 2. Vn vancal françés de figuras.

36. Vna guarniçión de çinta, cabo et feuilla et tachones de plata dentro vn esquerón colorado.

Otras joyas que enbió desde Coriel la señora condesa doña Leonor Destúñiga el año pasado de iUccccliii años et las resçibió el dicho Nuño de Gutierre de Valdelomar e de Bolaños, por quanto ge las dio para traer la dicha señora condesa por mandado del conde, my señor

37. Vna çinta de cuero con su cabo e feuilla dorados con nueue barres 38. Otra çinta con su escarçela et cabo e feuilla con sus bullones dorados.

39. Vn texillo con ocho granos de aljófar con cabos e feuillas dorados.

40. [Tachado: Vn vancal que enbió el dicho Juan de Pernía].

42. Vn vancal viejo que [tachado: enbió Juan de Pernía en Valladolid con] Pedro de Valda dio a Nuño en Valladolid.

43. Más dos vancales de figuras de Flandes traydos que dio Pedro de Valda a Nuño en Valladolid.

44. Çinco almohadas flandesas nuevas vasías con sus cueros colorados que resçebió de Gutierre de Valdelomar que le dio Juan Gonçales de Espinosa. 
45. Otras catorze almohadas flandesas nuevas vazías con sus cueros colorados a los suelos que resçibió del dicho Gutierre que le dio el dicho Juan de Espinosa.

Reçibiólas mi 46. Otras dos almohadas de cuero de guadameçil nueuas que resçibió señora del dicho Gutierre que le dio el dicho Juan de Espinosa e son vasías.

Reçibiólas mi señora

47. Otras ocho almohadas de cuero de guadamezil traydas vasías que reçibio del dicho Gutierre que le dio el dicho Juan de Espinosa con armas Destúñiga e de Guzmán.

Reçibiólo mi señora

48. Vn poyal flandesco en que ay quatro almohadas que resçibió de Gutierre que le dio Juan de Espinosa.

Reçibiólo mi señora

49. Vn vancal viejo con seys figuras e letras ençima de cada vna que resçibió de Gutierre que le dio Juan de Espinosa.

Reçibiólo mi 50. Vn vancal que enbió el dicho Juan de [tachado: Pernya] Espinosa. señora

\section{f. $5 r$}

\section{Alhonbras}

Tomola Juan de Pernía
51. Resçibió Nuño de Pedro de Valda vna alhonbra vieja.

52. Reçibio Nuño de my señora tres alhonbras viejas:

52. 1. Tres alhonbras nueuas.

52. 2. Otra alhonbra para el altar.

52. 3. Otra alhonbra nueva.

Reçiolas my 53. Otra alhonbra de las de Lorque grande et con las armas Destúñiga e de Guzmán e la enbió Pedro de Valda con Gutyerre de Valdelomar.

54. Vna alcatyfa blanca e verde trayda e la enbió Pedro de Valda con el dicho Gutierre de Valdelomar.

55. Vn vancal de alcatifa traydo que enbió el dicho Pedro de Valda con el dicho Gutierre de Valdelomar.

56. Vna alhonbra de Lorque nueua foradada de ratones que resçibió de Gutierre que le dio Juan de Espinosa. 
57. Otra alhonbra de Lorque trayda foradada de ratones que resçibió de Gutierre que le dio Juan de Espinosa.

58. Otra alhonbra pequeña de Lorque nueua que resçibió de Gutierre que le dio Juan de Espinosa.

\section{Reposteros}

59. Tyene el dicho Nuño tres reposteros de esparzidores de la deuisa del conde, my señor, los quales se fezieron en Valladolid año de iUccccliii años.

\section{f. $5 v$}

Reçibiólo my señora

Reçibióla my señora

Reçibio my señora las quatro en setienbre de liiii
60. Otro repostero verde de los de Flandes con perros e letras ençima dellos.

\section{Paramentos de cama}

61. Vna guarniçión de cama de Flandes de arboleda en que ay tres paños e vna sobrecama et las goteras nueuas, lo qual dyo Pedro de Valda al dicho Gutierre de Valdelomar.

62. [Tachado: Seys sargas verdes de cama] Seys sargas verdes.

\section{La cama del dicho señor}

Reçibiólos my

señora

Reçibiólos my

señora
63. Dos almofrejes de cama.

64. Quatro colchones.

65. Dos colchas.

66. Dos pares de sáuanas.

Reçibio my señora las quatro
67. [Tachado: Çinco pares de] Dies almohadas blancas.

68. Vna manta blanca. 
Reçibio my señora estas tres colchas e dio vna a don Pedro
69. Otras tres colchas que traxo Gutierre de Valdelomar que le dio Pedro de Valda, las dos de ellas de Flandes et la vna de lienço de la tierra.

70. Reçibio Nuño de my señora tres colchones nuevos en setienbre de liiii:

70. 1. [Tachado: Otros dos pares de sáuanas].

70. 2. Más le dio my señora ocho almohadas blancas.

70. 3. Dio my señora dos sáuanas de dos piernas cada vna.

70. 4. Otras dos sáuanas reales de tres piernas cada vna.

\section{f. $6 r$}

Nuño.

Cargo de la

cámara del

conde, my señor.

Año de

iUccccliiii años

71. Çinco cargas de algodón pardillas e amarillas.

72. Seys sargas verdes.

73. Más resçibió de Gutierre de Valdelomar que enbió en el Pedro de Valda tres sáuanas de lienço de Flandes nueuas cada vna de tres piernas.

74. Más resçibió del dicho Gutierre que enbió al dicho Pedro de Valda otra sáuana de lienço delgado nueuo de tres piernas.

\section{Cosas de lienço del dicho señor}

75. Dos camissas.

76. Vna linjavera con su peynador e dos pares de fazalejas et çiertos paños de nariçes.

77. Tres paños de cabeça, el vno entero et los dos medios.

78. Vna marjuleta.

79. Vn libro de resar con vna guarniçión de plata. 
80. Vna caxa para ençender lunbre.

\section{Otra ropa de camas}

Este almadraque $\mathbf{8 1}$. Vn almadraque real et otro amadraque de amarillo et azul con su real reçibiólo my lana et vna cabeçera de terlis, la qual era de la cama.

señora

f. $6 \mathrm{v}$

de las señoras, lo qual traxo Gutierre de Valdelomar que le dio Pedro de Valda.

82. Vn almadraque de terliz blanco et cardeno et el suso amarillo con su lana que traxo Gutierre que le dio Pedro de Valda.

83. Tres colchones de lienço de la tierra con su lana de los de la cama del conde, my señor, que Dios aya, et de las señoras que traxo Gutyerre que le dio Pedro de Valda.

84. Otro alfamares de amarillo et negro que traxo el dicho Gutyerre que le dio el dicho Pedro de Valda.

85. Otro alfamar de amarillo et colorado traydo que traxo el dicho Gutyerre que le dio el dicho Pedro de Valda.

Reçibiólas my

86. Dos mantas blancas, la vna de frisa et la otra de sayal traydas que señora traxo Gutyerre de Valdelomar que le dio Pedro de Valda.

87. Quatro paños de cama bordados et dos sargas coloradas, lo qual reçibió el dicho Gutyerre de Valdelomar que le dio el dicho Pedro de Valda.

My señora

88. Ytem, vna almadraquesa real trayda.

Reçibiólo my

señora

89. Vn cobertor de martas çercado de aseytuní colorado rico, aforrado en paño verde que reçibio de Gutyerre de lo que enbió Juan de Espinosa.

Dióse a la condesa de Sant

90. Otro cobertor de martas syn çercadura aforrado en paño colorado Esteuan

Reçibiólo my señora

91. Otro cobertor de cuero de garras pecas syn aforro que resçibió de Gutyerre que le dio Juan de Espinosa.

My señora

92. Otro cobertor de paño colorado aforrado en paño blanco que reçibió de Gutyerre que le dio el dicho Juan de Espinosa. 
My señora 93. Dos sargas e vn çielo broslados e en cada vno vn escudero et vna dueña e dos niños que resçibió de Gutierre que le dio el dicho Juan de Espinosa.

\section{f. $7 \mathbf{r}$}

Reçibiólas my señora

94. Vna colcha de lyenço de Flandes con vnas ruedas nueuas que traxo Gutyerre de Valdelomar que lo dyo Juan de Espinosa.

Reçibiólas my señora

95. Otra colcha de lienço trayda con veneras que traxo el dicho Gutyerre que le dio el dicho Juan de Espinosa.

Reçibiólas my 96. Otra colcha de lienço rota manzillada con obra de veneras que traxo señora el dicho Gutyerre que le dio el dicho Juan de Espinosa.

97. Vn faz de almadraque real de çinco piernas syn suelo My señora ni lana traydo que resçibió de Gutierre que le dyo Juan de Espinosa.

[Tachado: Dióse 98. Vna pieza de real colorado e amarillo en que ha dies Dióse a la a la condesa] varas e tres quartas que resçibió de Gutierre de Valdelomar condesa que le dyo el dicho Juan de Espinosa. de Sant

Esteuan

99. Otra pieça de real de amarillo e azul colorado nueuo en que ay dies varas que resçibió del dicho Gutierre que le dio el dicho Juan de Espinosa e es el cabo foradado.

My señora $\quad \mathbf{1 0 0}$. Otra pieça de contra real de amarillo e azul nueuo en que ha dies varas que resçibió de Gutyerre que le dio el dicho Juan de Espinosa.

My señora 101. Vna pieça de contra real amarillo e colorado en que ha seys varas e media que resçibió de Gutierre que le dio el dicho Juan de Espinosa.

My señora $\quad$ 102. Otra pieça de contra real amarillo e colorado en que ha dies varas e media escasas que resçibió de Gutierre que le dio el dicho Juan de Espinosa.

My señora

103. Otra pieça de contra real de amarillo e colorado en que ay dies varas que resçibió de Gutierre que le dio el dicho Juan de Espinosa.

My señora 104. Vna sarga verde trayda que resçibió el dicho Gutierre que le dio el dicho Juan de Espinosa.

\section{f. $7 \mathbf{v}$}


Paños françeses e alhonbras e almatifas e alhamares de estrado

My señora

My señora

My señora

My señora

My señora

My señora

My señora

My señora

My señora

f. $8 \mathbf{r}$

Nuño.

[Tachado: My señora] Cargo de la cámara del conde, my señor Año de iUccccliiii años
105. Tenya Nuño vn paño françés que le dio Juan de Pernía que tiene vnas figuras que paresçen que comen çereças, el qual le dio Juan de Pernya en Dueñas en el mes de abril de liii años.

106. Otro paño françés de vancales que le dio el dicho Juan de Pernía en la dicha Dueñas en el dicho mes de abril del dicho año.

107. Ytem, tyene más el dicho Nuño dos conpuertas de Flandes que le traxeron de Béjar.

108. Más tenya vna alcatifa con esparsidores.

109. Tenya más otra almatifa pequeña del altar.

110. Tenya más dos alhonbras para delante la cama.

111. Tenya más çinco almohadas de estrado.

Lo que resçibió el dicho Nuño de Gutierre de Valdelomar que lo enbió con el Pedro de Valda de la cámara que tenya del conde, my señor, que Dios aya, en el mes de disienbre de iUccccliii años es lo que sigue:

112. Reçibio de my señora vn paño françés de [en blanco].

113. Vn paño françés de la fama viejo.

114. Otro paño françés traydo del torneo.

115. Otro paño françés de caça et montería traydo.

116. Otro paño françés de monteria de oso traydo.

117. Dos mantas de pared de obra de Seuilla, la vna mayor en que ay figuras de saluajes, et en la otra vn león. 
118. Vn alfamar grande de beras blancas et coloradas My señora traydo.

119. Otro alfamar destrado de betas amarillas e prietas.

120. Vna alhonbra de las de Lorque grande con las armas Destúñiga e de Gusmán.

121. Vna alcatifa blanca et verde e colorada trayda.

122. Vn vancal de alcatifa traydo.

123. Vn repostero verde de los de Flandes con perros e letras ençima dellos.

124. Vna guarniçión de cama de Flandes de arboleda en que ay tres paños et vna sobrecama e las goteras nueuas.

125. Nueue almohadas de Flandes con sus figuras e suelos colorados vasías.

126. Dos vancales de Flandes nueuos con sus figuras e vnos conejos enrredados en cada vno.

127. Seys almohadas de cuero verde sylame et con armas Destúñiga traydas.

128. Dos alfamares de estrado, el vno de vías verdes e coloradas, et el otro de vias prietas e verdes, los quales dexara Pero Martines de Coriel en casa de Ferrand Ruys.

\section{Lo que resçibió de Gutierre que enbió Juan de Espinosa}

My señora

f. $8 v$

La condesa

My señora
129. Vn çielo françés con sus figuras de caça e con sus sortyjas.

130. Otro paño françés et en medio vna ave blanca grande como está metida en vna red.

131. Otro çielo traydo con flocaduras et figuras de caça como tyene vn bastón con amas manos.

132. Más otro paño françés nueuo pequeño de caça et en el vn escudero de vestuario asul con marcas et vna dama con vestidura colorada et con sus presillas ençima. 
My señora 133. Más otro paño françés traydo con dos escuderos et dos damas.

La condesa 134. Otro paño françés nueuo en el qual esta vna cama que tyene vna ropa de aseytuní çeniçienta con sus lauores et tyene en la mano la beca del capirote de vn escudero.

La condesa 135. Más otro paño françés nueuo de monte e de caça en el qual está vna figura que tyene dos falcones en la mano, el qual tyene vn capirote verde et çapatos con agujetas.

My señora 136. Más otro paño françés nueuo que se dize el paño de la liça et están en el como dos cauallos que estauan en canpo.

La condesa 137. Otro paño françés de monte de çieruos et de caça e de aves e está en el vn escudero que fase reuerençia a vna dama con unos capirotes verdes.

My señora 138. Otro paño françés nueuo de como pelean dos saluajes con vna bestia fiera et ençima están escuderos et damas et el escudero tyene vn ximio en las manos.

My señora

139. Más otro paño françés con damas et escuderos et en medio vna fuente.

My señora

140. Más otro paño françés con damas et escuderos con rosas e flores en las manos et en medio vna dama con vna vestidura colorada.

f. 9r

My señora

141. Más vna conpuerta de françés nueua en la qual esta vna dama et vn escudero grandes et al pie otras dos figuras pequeñas.

142. Vn vancal flandesco syn figuras.

143. Más vn paño françés de caça en medio vna mesa et como comen a ella vna dama et vn escudero e otros siruen et al pie vna fuente.

144. Más vna conpuerta de paño françés et en ella vna dama et vn escudero et el escudero vn falcón en la mano.

145. Otro paño seuillano viejo et en medio vna dama con vn capirote colorado et en la otra orilla vn escudero fyncada la vna rodilla.

146. Más otro paño françés de caça.

My señora 147. Más vna manta seuillana con saluajes et saluajas e los saluajes con caperuças en las cabeças et el vno como pelea con vn león et las saluajas con nyños en los braços. 
My señora 148. Vn alfamar grande de pies de vandas coloradas e verdes.

My señora 149. Otro alfamar de valdas verdes e moradas.

My señora 150. Más vn paño seuillano nueuo et en medio vn saluaje que pelea con vn león.

151. Vn paño françés pequeño nueuo de caça en el qual esta vn escudero entre las otras figuras con vna ropa verde et vnos capirotes blancos que fase contenença de fabla contra vna dama que tyene vn can por vna traylla la dicha dama, que resçibió de Gutierre de Valdelomar que le dio el dicho Juan de Espinosa.

\section{f. 9v}

\section{Armas}

152. Vnas platas que se conpraron en Valladolid año de iUccccliii años guarnidas con sus feuillas et texillos morados dorado con su alpartas.

153. Vn arnés de pyernas de la dicha guarniçión.

154. Vnos çapatos de asero del arnés con vnas espuelas postisas.

155. Vna armadura de braços trançado con sus museques de la dicha guarniçión.

156. Vna çelada con su rollo bordada de argentería et con muchas [en blanco] perlas et el casco de la çelada es de aljófar grueso et el rollo della es de masmenu daljófar.

157. Vna vandera de seda con sus vandas doradas de derredor con la vanda Destúñiga.

158. Vn estandarte.

159. Otra çelada blanca con su bauera que trae el paje, la qual dio el arçobispo de Toledo al conde, my señor.

160. Dos pares de espuelas doradas con sus texillos.

161. Vna espada françesa de armas guarnyda la çinta della el cabo e feuilla et contera et vna roseta et seys tachones de plata todo dorado.

162. Tiene más vna guarniçión de çinta que tenya la dicha espada el cabo e feuilla e tres tachones grandes con que se traua la dicha çinta et çinco pequeños todo dorado e esmaltada. 
163. Vna falda e goçeres e collarete, lo qual está puesto en vnas sayas azules.

164. Vn baúl de arras.

\section{f. 10r}

El dicho Nuño

Cargo de la

cámara del

conde, my señor

Año de

iUccccliiii años
165. Vnas fojas guarnidas en seda leonada con vn piastrón et vna camysa blanca para el sobre arnés.

166. Vna ropa de damasco pardillo que se viste sobre estas fojas.

167. Vn arnés de pyerrnas.

168. Vnos braçales

169. Vnos guardabraços

170. Vn elmete con vna bauera pequeña.

171. Otras fojas fuertes con sus mangas e alpartaz.

172. Yten, vna facha de armas.

173. Vna daraga et vna lança de mano que trae el paje e vn capaçete con bauera que le dio el arçobispo de Toledo al conde, my señor.

Dize Nuño que

174. Otra darga de anca fuerte e vnas espuelas gynetas.

es de Juan de

Pernía

175. Dos espadas roperas, la vna guarnyda de latón sobredorada.

176. Dos pares de borzeguíes.

177. Dos falsos petos negros de aseytuní negro de lauores.

178. Otro falso peto negro fustán.

179. Dos pares de calças de grana del arnés e vnas engorras. 
180. Vna espada morisca guarnyda de oro ynelada et esmaltada con cabo e feuilla e contera e su çinta e cabos e feuilla e quatro tachones e dos guarniçiones en que se traua la çinta.

181. Otra espada de la gyneta guarnyda en plata.

\section{f. $10 \mathrm{v}$}

182. Vnas encaladas de latón morisco sobredoradas et dos pares de ryendas de seda verde las vnas guarnydas.

183. Otras encaladas de plata sobredoradas con vnas borlas amarillas de seda.

184. Dos pedaços de cuero marroque arsón trasero e delantero de sylla gineta labrado de filo de oro e non está acabado.

185. Vna toca tuneçí.

186. Vn puñal coruo et dos ganiuetes en vna vayna.

187. Vnas cubiertas de cauallo napolitanas.

\section{Ropas de paño e de seda del dicho señor conde}

\section{Tenya el dicho Nuño las ropas que aquí dirá}

188. Dos baúles en que andan las ropas.

189. Vna ropa de estado de paño negro forrada en chamelote et desta ropa se fiso vna ropa corta para el conde, my señor, e aforráronla en martas et el chamelote del enforro tyénelo el dicho Nuño.

f. $11 \mathrm{r}$

190. Otra ropa pardilla de paño forrada en tapete negro, la qual se emendó e alargó con vn pedaço del mismo paño pardillo que tenya el dicho Nuño, et esta ropa se aforró en corderinas et el enforro del tapete negro fyncó et lo tyene el dicho Nuño, el qual enforro de tapete es de la çinta ayuso.

Reçibió my 191. Otra ropa de paño negra corta forrada en corderinas et quitóse el señora las fas enforrro de corderinas della e pusose en la ropa sobre dicha pardilla e desta ropa anplióse con dos corderinas que se traxieron de la feria de Medina del Canpo.

Reçibióla my 192. Otra ropa de fusteda negra et corta aforrada en frisa. señora 
Esta ropa dize

Nuño que dio a

Gonçalo Galindo

por mandado del

conde my señor

193. Otra ropa negra corta aforrada en paño negro.

194. Vn manto de paño negro.

Este capuz dio Nuño alcayde de Enzinas por mandado del conde
195. Vn capuz negro de paño.

196. Vna marlota negra de paño.

197. Vna jaqueta negra forrada en bocarán, la qual dio el conde, my señor, al dicho Nuño.

198. Quatro çamarrones blancos de cuero, los dos cortos et los otros dos largos.

199. Vn capirote de poner.

Diose a la condesa de 202. Vn capirote de vestir.

Santistevan

201. Vn sonbrero de befle pardillo.

202. Otro sonbrero de lana negro.

Dize Nuño que lo reçibio my señora

\section{f. $11 \mathrm{v}$}

Deste paño se cortó dos pares de calças para los señores pequeños e quedó en Nuño poco más de vna vara
203. Vn mongil de paño negro forrado en bocarán negro, et dize Nuño que mandó el conde, my señor, que deste enforro se fesiese vn enforro para los paramentos de su cauallo del conde, my señor, el qual enbió Pedro de Valda con Gutierre de Valdelomar.

204. Dos varas de paño escasas de Sant Juan que enbió Pedro de Valda con el dicho Gutierre de Valdelomar. 
Dize Nuño que dio este paño a Diego de Valera para faser vn manto para Juanín Lopes

Dize Nuño que le dio a Diego de Valera para faser briales a las donzellas de la condesa

[Tachado: dize que lo] Reçebio my señora

Reçibiólo my señora
205. Otro pedaço de ypre negro en que ouo tres varas menos sesma, que traxo Gutierre que le dio Pedro de Valda.
206. Otro pedaço de paño negro de Sant Juan tondido en que ouo catorse varas.

\section{Las cosas quel dicho Nuño reçibio de Gutierre de Valdelomar que le dio Pedro de Valda son las siguientes:}

207. Vn balandrán de grana aforrado en pardillo, el qual se desfyso por mandado del conde, my señor, para faser del vna ropa a Françisco, el paje de su merçet, para el dya del torneo.

208. Vn manto de escarlata colorado.

209. Vn mongil de chamelot verde aforrado en fustán.

210. Otro mongil de chamelote leonado aforrado en bocarán, el qual se desfizo e se aforró con el vna cota de damasco de la señora doña Eluira la delantera de la dicha cota.

Reçibiólo my 211. Vna corocha de paño pardillo senzilla.

señora

Reçibiólo my 212. Vn albornoz prieto de lana de cabras.

señora

f. 12r

\section{Jubones}

Diólo el conde, 213. Vn jubón de tapete pardillo.

my señor, a

Nuño

214. Vn jubón de azetuny negro, el qual dio a Nuño. 
215. Otro jubón de seda rasa negro, el qual dio a Françisco, su paje, para el torneo.

Reçibiólo my 216. Otro jubón de seda leonado viejo con mangas et collar de paño.

señora

217. Otro jubón nueuo pardillo de azeituní.

218. Otro jubón negro de lauores nueuo.

219. Vn jubón de satín negro nueuo que hera del conde, my señor, que Dios aya, el qual se dio por mandado del conde, my señor, para enforrar dos capelos de las señoras doña Leonor e doña Eluira.

220. Vn jubón de carmesí brocado que traxo Gutierre de Valdelomar que le dio el dicho Juan Despinosa. Fesieron del vn capelo de vestir para my señora doña Leonor.

f. 12v

\section{Ropas de paño e de vestir}

Este se dio para enforro de las mangas de las ropas del conde, my señor

Reçibiólo my señora

Reçibiólo my señora

Reçibiólo my señora

Reçibiólo my señora

Reçibiólo my señora

Reçibiólo my señora
221. Vn mongil prieto de bruneta frisada el qual resçibió del dicho Gutyerre que le dio el dicho Pedro de Valda.

222. Vna corocha prieta de bruneta aforrada en corderinas.

223. Vn mongil prieto viejo, el qual se dio por mandado del conde, my señor, para enforro de vna ropa al señor don Aluaro, su fijo.

224. Vn balandrán prieto senzillo de bruneta.

225. Otra corocha de bruneta prieta.

226. Vnas sayas blancas aforradas en lienço.

227. Vnas sayas negras aforradas en corderynas.

228. Vna çamarra nueua de cuero. 
Reçibiólo my señora

Reçibiólo my señora

\section{f. $13 r$}

Reçibiólo my señora

Reçibiólo my señora

Diólo a don

Pedro por mandado del conde

Reçibiólo my señora

Reçibiólo my señora

Reçibiólo my señora

Reçibiólo my señora
229. Vn manto de berna colorado viejo e roto.

230. Vna aljuba morisca de seda verde.

231. Dos bonetes negros e vno colorado.

Ropas de paño e de vestir que resçibió de Gutierre de Valdelomar que enbió con el Juan de Pernya que tenya Juan Despinosa

232. Vn mongil de damasco verde enforrado en paño verde.

233. Vnas mangas e pedaços de tapete pardillo que quedaron de vn mongil que se desfiso para jubones.

234. Vn manto de grana colorado.

235. Vn pelote de grana colorado.

236. Vna caperuça de grana colorada ytaliana.

237. Vnas sayas pardillas con seda negra en ruedo e en las mangas aforrada en paño verde.

238. Vnas sayas negras enforradas en paño negro.

239. Vna malrota verde con su cortapisa de argentería.

240. Vn manto de paño negro.

241. Vn capirote de poner negro.

242. Otro manto negro plegado.

243. Vnas sayas de monte verdes e en ellas vn pito e su caperuça. 
Reçibiólo my señora

Reçibiólo my señora

Reçibiólo my señora

Reçibiólo my señora

Reçibiólo my señora

Reçibiólo my señora

\section{f. $13 v$}

Reçibiólo my señora

Reçibiólo my señora señora

Reçibiólo my señora
244. Media vara de seda leonada con sus franjas.

245. Dos pares de calças coloradas.

246. Vna vara de paje leonada con sus trepas blancas.

247. Vn par de calças de ruán canelado.

248. Vn capus de chamelot leonado aforrado en amarillo.

249. Vnas faldillas de grana coloradas con sus franjas leonadas.

250. Vnas bragas de paño morado.

251. Vn pedaço de paño de manto negro.

252. Vn [tachado: quexote] queçote de lienço blanco con sus randas e franjas de oro e syrgo verde.

253. Vna tira bragueta de cordellate blanco.

254. Otras medías calças de paño mesclado.

255. Otras calças verdes viejas.

256. Media pieça de fustán.

257. Vn bonete de grana colorado.

258. Otro bonete morado.

259. Otro bonete negro.

260. Vn bonete negro traydo.

261. Vn bonete morado traydo. 
Reçibiólo my señora

262. Vnas luas de grana coloradas enforradas en peña de buytre.

263. Vnas sayas blancas sensillas con corchetes.

\section{Calças}

264. Dos pares de calças negras.

265. Otros dos pares de calças de grana.

Reçibiólo my señora

\section{f. $14 r$}

Al dicho Nuño

Cargo de la

cámara del dicho

señor conde

Año de

iUccccliiii años

Reçibiólo my

señora

Reçibiólo my

señora

Reçibiólo my

señora

266. Otros tres pares de calças de blanqueta.

\section{Arcas e cofres e mesas}

267. Vn cofre de Flandes chapado con dos çerraduras.

268. Otros dos cofres chapados.

269. Vn cofre pequeño ferrado.

270. Otros dos cofres pequeños verdes, el vno reçibiólo my señora.

Reçibiólos my 271. Quatro arcas ensayaladas de madera de paño blanco et la vna de señora paño negro.

272. Otra arca ensayalada de paño verde.

273. Vna mesa que dio al dicho señor el abad de Sant Fagund con vn par de vancos.

274. Otra mesa con vn par de vancos.

275. Vna escalera de enparamentar de tres pedaços. 


\section{Otras cosas menudas}

276. Vna silla de fierro con quatro mançanas en que oye misa el conde, my señor, que se conpró en Valladolid.

277. Vn almofrex pequeño.

278. Ocho sillas de cuero de asentar et [en blanco].

279. Otras dos sillas de paño.

280. Vn moscadero con las armas Destúñiga.

f. 14v

281. Vnas alforjas pequeñas de camino con vna bota.

282. Dos cueros de chamoçes.

283. Vna maleta de cuero con dos pares de botas e çiertos pares de çapatos.

284. Vna silla de asentar et vn baçín de latón et vna sarga vieja colorada.

285. Seys ramales de apretar asemilas que reçibio del dicho Gutierre de Valdelomar que le dio el dicho Juan de Espinosa.

286. Catorze cabestros de sedas que resçibió de Gutierre que le dio el dicho Juan de Espinosa.

287. Dos çinchas de lana para asemilas que resçibió del dicho Gutierre que le dio el dicho Juan Despinosa.

288. Quatro cabeçadas de asemilas todo ello nueuo que resçibió del dicho Gutierre que le dio el dicho Juan Despinosa.

289. Dos bretes de fyerro que resçibió del dicho Gutyerre que le dio el dicho Juan Despinosa.

290. Dos pares de lazos de cáñamo nueuos que resçibió del dicho Gutyerre que le dio el dicho Juan Despinosa.

f. $15 r$

\section{Lyenços}

Que resçibió el dicho Nuño de Gutierre de Valdelomar que enbió con el Pedro de Valda las cosas que aquí dirán en esta guisa: 
291. Vn pedaço de lienço de la tierra curado en que ouo ocho varas.

292. Otra pieça de lienço curado delgado en que ouo quinse varas escasas.

293. Otra pieça de lienço curado delgado en que ouo dose varas.

Deste lienço

294. Otra pieça de lienço curado delgado en que ouo treze varas e mando el conde, my señor, a destas trese varas dise Nuño que le mandó el conde, my señor, enviar Nuño que feziese las dose dellas para camysas a doña Eluira, su fija, asy que fyncó vna vna sáuana de tres lienços para el aparador de las ropas del dicho señor en que entraron xviii varas e quarta $\mathrm{e}$ más xxii varas que enbió a doña Eluira para camysas vara en el dicho Nuño.

295. Otra pieça de lienço curado delgado en que ouo treze varas escasas.

296. Otra pieça de lienço delgado curado en que ouo dose varas.

Todo lo otro dise que lo dio a my señora

297. Vn pedaço de cáñamo en que ay çinco varas e tres terçias nueuo, lo qual traxo el dicho Gutyerre que le dio el dicho Juan Despinosa.

298. Vna sáuana de lienço de la tierra de quatro pyernas trayda que resçibió del dicho Gutyerre que le dio el dicho Juan Despinosa.

\section{f. $15 v$}

[En blanco $]$

f. 16r

Reçebta de

En Coriel en xv días de enero año de cccclv años el conde, nuestro la cámara del señor, mandó a León el contador que por quanto Nuño auía reçibido conde, my señor. Año de iUcccelv las cosas de su cámara de las quales auia dado algunas dellas por su mandado así a my señora doña Leonor Pimentel como a mosén Diego de Valera e a otras personas que me mandaua e mandó que requeriese la cámara con el dicho Nuño e estuviesen todas las cosas que en la dicha cámara fallase e las cosas que yo el dicho contador fallé que tenya el dicho Nuño en la dicha cámara el dicho día son las siguientes: 
Primeramente las joyas que se fallaron en la dicha cámara son las que se siguen:

299. Vn collar de oro que se fizo maestre Hançe de Valladolid e cabolo en Aréualo, el qual pesa siete marcos e vna onça e vna ochaua e está entero que non le fallesçe cosa alguna e tiene siete balaxes e seys esmeraldas e siento e treze perlas de aljófar, las dose dellas grandes e las medianas.

300. Vna çinta de oro de caderas en que ay dos rencleras de los cabos de ambas partes que ay en cada parte nouenta muelas de oro que son çiento e ochenta muelas, e más en medio de la dicha çinta sus tachones de oro como en manera de enfojadura que non fallesçe cosa alguna en ella, et más dos agujas de oro con que se çiñe la dicha çinta, que pesa seys marcos e quatro ochauas de oro bien otorgado en su caxa.

301. Vn collar de oro en que ay veynte mienbros redondos de esparçidores que pesa vn marco e çinco onças e siete ochauas.

f. 16v

302. Otro collar de oro en que ay treynta e syete mienbros de lazadas que pesa dos marcos e dos onças e vna ochaua de oro.

303. Vna cadena de oro que pesa seys marcos e quatro onças e tiene setenta e ocho eslauones.

304. Vna çinta de caderas de plata sobre dorada en tres pedaços pegadizos que pesa siete marcos e quatro ochauas.

305. Vna çinta de texillo negra con cabo e feuylla de oro con esparzidores en el cabo e en la feuylla e con seys tachones en la dicha çinta e vn carniel de damasco negro viejo guarnido de plata.

306. Vna çinta de cuero angosta con cabo e feuylla de oro e vna copa gorja con vna contera de oro.

307. Vn cofre en que andan estas dichas joyas.

\section{f. $17 \mathbf{r}$}

Nuño

Reçebta de la cámara del dicho señor conde Año de iUcccclv

\section{Ropas de seda e paño de vestir del conde, my señor}

308. Vna ropa de estado de tapete negro aforrada en martas.

309. Otra ropa de paño negro de estado aforrada en seda negra rasa. 
310. Otra ropa de paño leónada de estado aforrada en [tachado: paño] seda rasa pardilla.

311. Vna ropa de paño negro corta aforrada en martas.

312. Otra ropa de paño pardillo corta forrada en tapete negro.

313. Otra ropa de paño negro corta forrada en chamelote blanco.

314. Otra ropa de paño pardillo de estado aforrada en corderinas.

315. Dos capirotes de [tachado: vestir] poner.

316. Vn manto de paño negro.

317. Vn manto pardillo.

318. Otro manto de paño negro todo plegado.

f. $17 \mathrm{v}$

319. Vna marlota de paño negro.

320. Vna capa de paño negro.

321. Vna jaqueta de paño pardillo forrada en corderinas.

322. Vn capuz de paño pardillo de Valladolid.

323. Vnas sayas de ruán de monte con su puerta e dos pares de mediascalças.

324. Otras sayas verdes.

325. Vna loba de ruán pardillo forrada en raposos.

326. Quatro çamarones.

327. Vn albornoz de lana de cabras.

328. Siete bonetes, los çinco prietos e dos colorados et más vno morado, que son ocho e vna caperuça de grana grande.

329. Vnas mangas de tapete pardillo.

330. Vnas sayas blancas en que esta enbuelto el arnés. 
331. Vn manto de bernya colorado.

\section{f. $18 r$}

\section{f. $18 v$}

\section{f. $19 r$}

Nuño

Cámara. Año de cccelv

\section{Jubones}

332. Vn jubón de azeytuny pardillo.

333. Otro jubón de azeytuny negro alcachofado.

334. Otro jubón de damasco negro de alcachofa.

335. Tres pares de calças negras e dos pares de galochas, las vnas llanas e las otras de lienso labradas.

336. Vn sonbrero de befle pardillo.

337. Otro sonbrero de lana negro.

338. Quatro baúles en que andan estas ropas.

339. Vn doser de paño pardillo e leonado de esparzidores del aparador de las ropas e vna sáuana grande.

\section{La cama del dicho señor}

340. Tres colchones grandes nueuos de lienço de Flandes.

341. Dos colchas, vna grande e otra más pequeña.

342. Vn cobertor de garras prietas con apañaduras de chamelote verde con vnas jarras de oro broladas.

343. Tres pares de sáuanas de la cama, que son las dos dellas de lienço de Flandes e las otras de lienço castellano.

344. Otras tres sáuanas que andan en los baúles con las ropas del conde, my señor.

345. Vna manta blanca.

346. Çinco sargas coloradas broslada con vnos letriles.

347. Ocho almohadas de cabeçera. 
348. Vn almofrex en que anda toda esta cama.

349. Vna sarga verde e [en blanco].

350. Otra sarga colorada.

f. 19v

351. Vn repostero pardillo e leonado de la cama con esparzidores e las armas Destúñiga en medio.

352. Otros tres reposteros verdes con esparzidores.

f. $20 \mathrm{r}$

\section{Cosas de lienço del conde, my señor}

353. Quatro camysas.

354. Quatro cubrecheles.

355. Vna barjolete con su peynador e dos pares de fazalejas e çiertos paños de narizes.

356. Dos medios paños de cabeça.

357. Vna barjoleta.

358. Vn libro de rezar cubierto de tapete negro con vna guarniçión de plata.

359. Vna caxa para ençender lunbre.

\section{f. $20 \mathrm{v}$}

\section{Los libros quel dicho señor tiene en la cámara son estos}

360. Vn libro del testo primero del regimyento de los prinçipes.

361. La coronyca del rey don Ferrando el magno.

362. Otro libro del regimyento de los pínçipes en romançe e el trato del rey don Ferrando.

363. Otro libro que fizo el obispo de Cuenca del tratado de caso fortuno.

364. Otro libro del marmotreto.

365. Vna briuia escripta en latyn.

366. Vnos quadernos de pergamyno [tachado: de] que comyença en la coronyca del rey don Enrique terçero. 
367. Vn libro escripto en latyn cubierto de cuero colorado.

368. Vn libro de Consideraçione.

369. Otra corónica de [en blanco].

f. $21 \mathrm{r}$

Nuño. Cámara. Año de lv

\section{Otra ropa de cama que enbió Pedro de Valda con Gutierre de Valdelomar}

370. Vn almadraque grande que tiene el suelo azul e la fas amarilla.

371. Otro colchón que esta amazillado e roto.

372. Otro almadraque que tiene el suelo amarillo e la fas la meytad blanca e la meytad azul de fustán.

373. Otro colchón grande traydo.

374. Otro colchón pequeño poco traydo.

375. Vna cabeçera de terlis.

376. Cinco alfamares, los quatro dellos de amarillo e negro e el otro de amarillo e colado.

377. Dos mantas blancas, la vna de frisa e la otra de sayal.

\section{f. $21 \mathrm{v}$}

f. $22 \mathrm{r}$

Nuño. Cargo.

Año de cccclv

378. Dos conpuertas de Flandes.

379. Vn vancal.

380. Tres paños françeses, los dos traydos et el vno nueuo.

381. Çinco alhonbras e alcatifas.

f. $22 v$

\section{Otras cosas menudas}

382. Vna silla de fierro con sus almohadas en que oye mysa el conde, my señor. 
383. Vna arca blanca en que anda esta dicha silla.

384. Vn cofre pequeño ferrado de escripturas del conde, my señor.

385. Vn cofrezillo verde.

386. Vna arca verde pequeña con confites e con conseruas.

387. Vna arca colorada con escripturas.

388. Vn almofrex pequeño con vna maleta.

389. Vna maleta con dos pares de borceguíes e dos pares de botas e çiertos pares de çapatos.

390. Dos pares de çapatos bordados.

391. Ocho sillas de cuero de asentar e dos sillas de palo que están en Valladolid.

f. $23 r$

392. Vn moscadero con las armas Destúñiga.

393. Vnas alforjas de camyno con vna bota.

394. Dos cueros de chamoçes.

395. Vna silla de asentar e vn baçín de latón e vna sarga vieja colorada.

396. (Al margen, a la izquierda: Seys ramales de apretar azémylas)

397. Dos bretes de fierro.

398. (Al margen, a la izquierda: Onze cabestros)

399. Vn marco de dies e seys marcos con su balança.

400. (Al margen, a la izquierda: Dos çinchas de lana).

401. Vn ferramental nueuo de ferrar con su aparejo.

402. (Al margen, a la izquierda: Vna cabeçada de zemylas).

403. Otro ferramental del arnés. 
404. (Al margen, a la izquierda: Dos pares de laços nueuos).

405. Otro ferramental con martillo e tenazas para enparamentar.

406. Vn [tachado: palo] bastón estacado que le dio Pedro de Astorga.

407. Vnas escalas.

408. Dos viuelas con sus casas de paño.

409. Vna vallesta de mote con çinto e polea e aljaua.

410. Vna carmallera.

f. $23 \mathrm{v}$

411. Vn çinto de lobo con su esquerón e vn nauajon e vna traquera de plata.

412. Dos nauajones en vna caxa.

413. Vn cordón de sirgo pardillo de çeñyr.

414. Dos culebrinas e seys viratones et vna talega con póluora en vna arca vieja.

415. Vna arca zul con la ferramyenta del conde, my señor.

416. Vna guarniçión de adarga de plata con sus borlas.

f. $24 r$

Nuño. Cámara

Año de cccclv
417. Vnas platas que se conpraron en Valladolid año de iUccccliii años guarnydas con sus feuillas e texillos morados dorado con su alpartas.

418. Vn arnés de piernas de la dicha guarniçión.

419. Vna guarniçión de braços trançado con sus museques de la dicha guarniçión.

420. Vnos çapatos de azero del dicho arnés con vnas espuelas postizas.

421. Vna çelada con su rollo bordada de argentería e con muchas perlas et el casco de la çelada es de aljófar grueso et el rollo della es de más menudo aljófar.

422. Vna çelada blanca con su bavera que trae el paje. 
423. Vnas manoplas.

424. Vn falso peto de seda e vnas calças e çapatos.

425. Vn baúl en que anda este dicho arnés.

426. Vnas fojas guarnidas en seda leonada con vn puastrón e [en blanco].

f. $24 v$

427. Vna ropa de damasco pardillo que se viste sobre estas fojas.

428. Vna camysa blanca para sobre el arnés.

429. Vn arnés de piernas.

430. Vnos braçales e vnos guardabraços.

431. Vnas sayas con falda e goçetes e vn collarete.

432. Vn elmete con vna bavera pequeña.

433. Vna [Tachado: b] testera de cauallo.

434. Vn falso peto de seda e otro de fustán e tres pares de calças.

435. Vn baúl en que andan todas estas cosas.

436. Vnas fojas fuertas con sus mangas de alpartas.

437. Vna espada de armas con cabo e feuilla e seys tachones de plata sobredorada.

438. Vna fachan de armas.

439. Vna copa gorja para el arnés.

440. Dos pares de espuelas doradas.

441. Vna silla de cauallo de la guisa bordada de latón.

442. Dos pares de cubiertas, las vnas blancas e las otras coloradas con sus cortapisas.

\section{f. $25 r$}


443. Vnos paramentos de tapete leonado e pardillo con esparzidores bordados de aljófar e argentería.

444. Vna darga e vna lança que trae el paje.

445. Vna bandera de seda con sus vandas doradas enderredor con la vanda Destúñiga.

446. Vn estandarte.

447. Vna guarniçión de espada en vna çinta que tenya la espada françesa con cabo e feuilla e tres tachones grandes e con otros çinco tachones pequeños todo dorado e esmaltado.

448. Dos espadas roperas, la vna guarnida de laton sobre dorada.

449. Vna espada que traxo Pero Martines de Toro a Gibraleón que copo al conde, my çseñor, de ¿laonsero?

450. Vna espada morisca guarnyda de oro encalada e esmaltada con cabo e feuylla e contera e su çinta e cabos e feuylla e quatro tachones e dos guarniçiónes en que se traua la çinta.

451. Otra espada de la gyneta guarnida en plata.

f. $25 v$

452. Vnas encaladas de latón morisco sobredoradas e dos pares de riendas de texillo verde, las vnas guarnidas.

453. Otras encaladas de plata sobredoradas con vnas borlas amarillas

454. Vnos cordones de encaladas [Tachado: de] que dio don Diego Destúñiga al conde, my señor.

455. Dos pedaços de cuero marroque arçón e trasero e delantero de silla gineta labrado de filo de oro e non esta acabado.

456 Otra toca tuneçi.

457. Vn puñal corvo e dos canyvetes en vna vayna.

f. 26r

Muy magnífica señora, las cosas que Catalina de Seuylla reçibió por mandado de vuestra merçed de Juan de Pernya en Coriel en sábado xxiiii días de mayo deste año de iUcccciiii años, las quales el dicho Juan de Pernya avya reçibido de la condesa doña Leonor Destúñiga son las que aquí dirán en esta guisa: 


\section{Primeramente}

458. Vna caxa en que está la media de argentería.

459. Vna bolsa broslada de alxófar e con botones de alxófar e esta dentro en ella siete perlas de aljófar, et esta dentro en ella siete perlas de aljófar e çierto aljófar menudo e vna buxe de alanbar.

460. Vn cofrezillo ferreteado que esta dentro çierto aljófar ensartado con cuentas azules e más çinco soles esmaltados con aljófar e vna crus dentro con quatro perlas e vn balax en medio e más vna cadenylla de plata e todo esto está dentro en el dicho cofre e más tres balajes e otro engastonado e dos dimantes e más vna sortija de oro.

461. Vna buxeta de plata.

462. Vna calabaçala de plata.

463. Vn braseruelo.

464. Vn sahumador.

465. Vna arquetilla ferreteada con çiertas cuentas de coral dentro en ella e otras cuentas de azauache e unos ganyuetes con su vayna de plata e vnos antojos guarnidos de plata e vnas cuentas de plata.

466. Vna pastilla de plata.

\section{f. 26v}

467. Vn calter de plata.

468. Vn anus dey de plata.

469. Vnas cuentas de ánbar.

470. Otra arquilla de plata ferreteada.

471. Quatro almohadas broladas e vn trauesero.

472. Vn cofrezillo dorado.

473. Vnas orillas azules broladas $[\mathrm{sic}]$.

474. Otra almohada azul.

475. Vn trauesero negro brolado e vnas orillas negras brosladas. 
476. Vna çestilla de vidro dorada.

477. Vn pito.

478. Vna caxa con vn espejo.

479. Vn peso.

480. Vnas cuentas de linaloe.

481. Tres almohadas broladas con aljófar pequeñas e otras dos syn aljófar.

482. Vn almayzar blanco con orillas de oro.

483. Otro almayzar con orillas coloradas.

484. Vnas orillas de seda moradas de cama.

485. Tres tocas moriscas bronidas.

486. Vna cuchara de plata con pedaços de coral

487. Vn espejo.

488. Vn pedaço de lienço delgado.

489. Otro pedaço de lienço grueso.

490. Vn pedaço de tocas delgado.

491. Otro pedaço de tocas.

492. Otro pedaço de lienço.

493. Otros dos pedaçuelos de lienço delgados.

494. Vnas fasalejas broladas.

f. $27 r$

495. Vn pedaço de lienço grueso.

496. Vn pedaço de lienço delgado.

497. Vna almohada broslada de oro. 
498. Otra almohada blanca.

499. Otra almohada labrada de seda.

500. Vn peynador con randas de oro.

501. Vn frutero labrado.

502. Vna camysa broslada de oro.

503. Otro frutero broslado de seda.

504. Otros siete fruteros labrados de oro e de seda.

505. Vnas randas de filo de oro e de sirgo.

506. Vna crus de filo de oro e de sirgo.

507. Otros çinco pedaçuelos de lienço delgados.

508. Dos pedaçuelos de lienço de Flandes.

509. Vna toca de seda.

510. Vn pedaçuelo de lienço delgado.

511. Otros tres pedaçuelos de lienço delgados.

512. Vn pedaço de Canbray con flocaduras.

513. Vna palia de lienço labrada de seda con vna crus en medio.

514. Vn paño con sahumaduras.

515. Vn frutero es començado a labrar.

516. Dos pedaços de lienços bastos.

517. Vna cuchara de jaspe.

518. Vn pedaço de lienço delgado.

f. $27 \mathrm{v}$

[En blanco] 
f. $28 \mathrm{r}$

En el mes de mayo año de iUccccliiii años dio Catalina de Seuilla por mandado de my señora doña Leonor Pimentel para lleuar con el conde, my señor, a Nuño, su camarero, a la corte del rey, nuestro señor, estas cosas seguientes:

\section{Primeramente}

519. Dos colchas.

520. Tres pares de sáuanas.

521. Ocho almohadas de cabeçera.

522. Dos paños françeses.

523. Las sargas amarillas et pardillas.

524. Tres alhonbras.

525. Vna manta destirador.

526. Doze almohadas, diéronse ocho non más.

527. Vn paño françés e dos vancales.

f. 28v

\section{f. 29r}

[En blanco $]$

Pedro de Ferrera, cauallerizo del conde, my señor

Pedro de Ferrera, cauallerizo

Cargo de cauallos et mulas et otras cosas que pertenesçen a ellas.

Año de

iUccccliiii años
Los cauallos e mulas e otras cosas que resçibió Pedro de Ferrera, cauallerizo, por mandado del conde, my señor, para tener en su caualleriza, las quales le fueron entregadas en el mes de enero año de iUccccliiii años, las quales son las que adelante en esta guisa:

\section{Primeramente}

528. Vn cauallo houero.

529. Otro cauallo ruano de la lança. 
530. Otro cauallo ruçio grande que dio el prior de San Juan al conde, my señor, el qual dio el dicho señor a mosén Dyego de Valera et tomóle otro cauallo castaño houero, el qual dyo el dicho señor a la señora reyna de Castilla que ge lo demandó.

531. Vna yegua castaña.

532. Vna mula pardilla.

533. Otra mula castaña esenra que dio Alfonso Áluares, contador, al conde, my señor.

\section{f.29v}

\section{Sillas et frenos que tyene el dicho Pedro de [Tachado: Val] Ferrera}

534. Vna sylla de cauallo de la guisa.

535. Otra silla gyneta en que trae la lança.

536. Vn freno con sus encaladas que trae el cauallo de la lança.

537. Vna brida que trae el cauallo houero.

538. Vnas espuelas que trae el paje.

539. Vna sylla de mula llana en que anda de continuo el dicho conde.

540. Otra sylla sardesca de mula en que anda el dicho señor por camyno.

Esto es del cargo

de Nuño

\section{Otras syllas}

541. Vna silla de la guisa de cauallo que se conpró en Valladolid.

542. Otra sylla de mula labrada de huesso que le dio Sancho, secretario, en Coriel.

543. Vnos estribos dorados.

544. Vna coraça de silla de mula, la qual coraça es pardilla con su coxinete que traxo Gutierre de Valdelomar que le dio Pedro de Valda.

\section{f. 30r}

Esto es del cargo de Nuño

\section{Ballestas e culebrinas}


545. Vna ballesta de asero de monte con su çinto e aljaua et polea de dos poleas et çiertos viratones.

546. Otra ballesta de asero que le dio Escalante al conde, my señor.

547. Cuatro culebrinas con su caxa e vn ferramental con martyllo et tenasas e çiertos viratones e vna talega de póluora, de las quales dichas quatro culebrinas dyo el conde, my señor, al comendador de Banba en el mes de disienbre del año de iUccccliii años las dos dellas et las otras dos fyncaron en el dicho Nuño.

\section{BIBLIOGRAFÍA UTILIZADA}

Alfau de Solalinde, Jesusa. Nomenclatura de los tejidos españoles del siglo XIII. Madrid, 1969.

Benito Ruano, Eloy. "Lope de Estúñiga. Vida y cancionero", Revista de Filología Española, LI (1968), pp. 17-20.

Calderón Ortega, José Manuel. Álvaro de Luna: Riqueza y poder en la Castilla del siglo $X V$. Madrid, 1998.

Cañas Gálvez, Francisco de Paula. El itinerario de la corte de Juan II de Castilla (1418-1454). Madrid, 2007.

—. "Las casas de Isabel y Juana de Portugal, reinas de Castilla. Organización, dinámica institucional y prosopografía (1447-1496)", en Las relaciones discretas entre las monarquías hispana y portuguesa. Las casas de las reinas (siglos $X V$-XIX), Vol. I. Madrid, 2008, pp. 91-231.

—. "La cámara de Juan II: vida privada, ceremonia y lujo en la corte de Castilla a mediados del siglo XV", en Evolución y estructura de la Casa Real de Castilla, Vol. I. Madrid, 2010.

—. "La Casa de Juan I de Castilla: aspectos domésticos y ámbitos privados de la realeza castellana a finales del siglo XIV (ca. 1370-1390)" En la España Medieval 34 (2011), pp. 133-180.

- Burocracia y cancillería en la corte de Juan II de Castilla (1406-1454). Estudio institucional y prosopográfico. Salamanca, 2012.

Cátedra, Pedro Manuel. La historia de la Casa de Zúñiga, atribuida a Mosén Diego de Valera. Salamanca, 2003.

Chacón, Gonzalo. Crónica de Don Álvaro de Luna, Edición de Juan de Mata Carriazo. Madrid, 1940.

Diago Hernando, Máximo. La industria y el comercio de productos textiles en Europa. Siglos XI al XV. Madrid, 1998.

Ferrandis Torres, José. Fuentes documentales para la historia del arte español, III. Madrid, 1949.

Franco Silva, Alfonso. La fortuna y el poder: estudios sobre las bases económicas de la aristocracia castellana. Cádiz, 1996. 
—. "La cámara del cardenal Mendoza. Lujo, riqueza y poder de un príncipe de la Iglesia hispana del siglo XV", Historia, Instituciones, Documentos 39 (2012), pp. 65-127.

Gómez Vozmediano, Miguel Fernando. "La gestión patrimonial de la aristocracia castellana. Burocracia señorial, práctica contable y reflejo documental (siglos XV-XVIII)", en Comercio, banca y sociedad en los reinos hispánicos (siglo $X I V$-XVIII), Ángel Alloza Aparicio, F. Fernández Izquierdo y Elena García Guerra (eds.). Madrid, 2012, pp. 227-278.

Gual Camarena, Miguel. Vocabulario del comercio medieval: colección de aranceles, aduaneros de la corona de Aragón (siglos XIII y XIV). Tarragona, 1968.

Herráez Ortega, María Victoria. "De la plata y los plateros del Rey Juan II de Castilla”, en Estudios de platería, J. Rivas Carmona (Coord.). Murcia, 2006, pp. 227-289.

Ladero Quesada, Miguel Ángel. “Los señores de Gibraleón”, Cuadernos de Historia, VII (1977), pp. 33-95.

—. "Rentas condales en Plasencia" en El Siglo XV en Castilla. Fuentes de renta y política fiscal. Barcelona, 1982, pp. 168-189.

—. "1462: Un año en la vida de Enrique IV, rey de Castilla", En la España Medieval 14 (1991), pp. 237-274.

—. "La Casa Real en la Baja Edad Media", Historia, Instituciones, Documentos 25 (1998), pp. 327-350.

Ladero Quesada, Miguel Ángel y Cantera Montenegro, Margarita. "El tesoro de Enrique IV en el alcázar de Segovia 1465-1475”, Historia, Instituciones, Documentos 31 (2004), pp. 307-352.

Ladero Quesada, Miguel Ángel y Quintanilla Raso, María Concepción. "Bibliotecas de la alta nobleza castellana en el siglo XV" en Livre et lecture en Espagne et en France sous l'Ancien Régime, Colloque de la Casa de Velázquez. París, 1981, pp. 47-59.

Les entourages princiers à la fin du Moyen Âge. Une aproche quantitative, Études réunies par Alexandra Beauchamp. Madrid, 2013.

Lora Serrano, Gloria. "Nobleza y monarquía bajo los primeros Trastámaras: el ascenso de Diego López de Estúñiga”, Ifigea 3-4 (1986-1987), pp. 73-108.

—. "La organización de la defensa militar de un estado señorial y el potencial bélico de un noble a mediados del siglo XV", Historia, Instituciones, Documentos 18 (1991), pp. 297-338.

—. "El ducado de Arévalo (1469-1480). Un conflicto señorial en tierras abulenses a fines de la Edad Media", Historia, Instituciones, Documentos 25 (1998), pp. 369-394.

—. "Los constructores del Palacio de Altamira. La familia señorial de los Estúñigas”, en La restauración del palacio de Altamira. Sevilla, 2005, pp. 126-179.

Martínez Martínez, María y Lora Serrano, Gloria. "Las inversiones suntuarias de la nobleza a fines de la Edad Media" en Historia y sociabilidad: homenaje a la profesora María del Carmen Melendreras Gimeno, Juan Bautista Vilar 
Ramírez, Antonio Peñafiel Ramón y Antonio Irigoyen López (coords.). 2007, pp. 197-222.

Martínez Moro, Jesús. La renta feudal en la Castilla del siglo XV, los Stúñiga: consideraciones metodológicas y otras. Valladolid, 1977.

Moya García, Cristina. Edición y estudio de "La Valeriana" (Crónica abreviana de España de Mosén Diego de Valera. Madrid, 2009.

Nieto Soria, José Manuel. "El tesoro de doña Leonor, esposa de Fernando I de Aragón, en el monasterio de Guadalupe", Acta historica et archaeologica mediaevalia 18 (1997), pp. 39-66.

- Un crimen en la corte. Caída y ascenso de Gutierre Álvarez de Toledo, Señor de Alba (1376-1446). Madrid, 2006.

Ortega Álvarez, Javier. "La Casa de Don Gutierre de Sotomayor, Maestre de Alcántara: Una aproximación a la prosopografía de la Orden de Alcántara", Revista de Estudios Extremeños, 2010, Tomo LXVI (1), pp. 239-286.

Ostos Salcedo, Pilar. La Orden de Santiago y la escritura. El valor de la comunicación escrita en una orden militar. Los establecimientos de 1440. León, 2008.

Pérez de Guzmán, Fernán. Crónica del serenisimo príncipe don Juan, segundo Rey deste nombre. Madrid, 1953.

Pulgar, Fernando de. Claros varones de Castilla, Edición de M. A. Pérez Priego. Madrid, 2007.

Salazar y Acha, Jaime de. La Casa del Rey de Castilla y León en la Edad Media. Madrid, 2000.

Torre, Antonio de la. "Servidores de Cisneros", Hispania 23 (1946), pp. 179-241. Villalobos y Martínez-Pontrémuli, María Luisa. "Los Estúñiga: la penetración de Castilla de un linaje de la nobleza nueva", Cuadernos de Historia 35, Extra 6 (1975), pp. 327-356.

—. "Las gestiones hacendísticas de Diego López de Estúñiga, camarero de Juan I (Contribución al estudio de la economía y la fiscalidad castellanas bajo los primeros Trastámaras)", Hispania Vol. 43, nº 153 (1983), pp. 159-207.

V.V.A.A. Evolución y estructura de la Casa Real de Castilla, A. Gambra Gutiérrez y F. Labrador Arroyo (coords.). Madrid, 2010 (2 vols.).

Fecha de recepción del artículo: noviembre 2013

Fecha de aceptación y versión final: julio de 2014 
